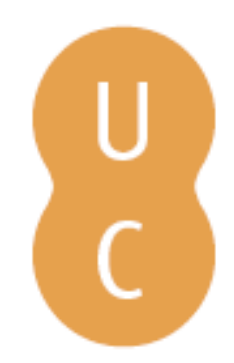

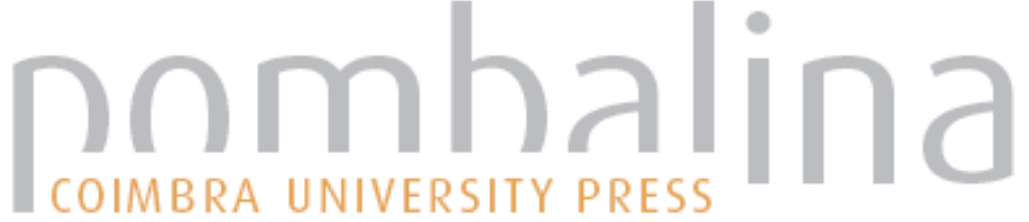

\section{Doenças cardíacas mais comuns}
Autor(es):
Pires, António
Publicado por: Imprensa da Universidade de Coimbra
URL persistente:
URI:http://hdl.handle.net/10316.2/43142
DOI:
DOI:https://doi.org/10.14195/978-989-26-1300-0_41

Accessed : $\quad$ 26-Apr-2023 05:07:39

A navegação consulta e descarregamento dos títulos inseridos nas Bibliotecas Digitais UC Digitalis, UC Pombalina e UC Impactum, pressupõem a aceitação plena e sem reservas dos Termos e Condições de Uso destas Bibliotecas Digitais, disponíveis em https://digitalis.uc.pt/pt-pt/termos.

Conforme exposto nos referidos Termos e Condições de Uso, o descarregamento de títulos de acesso restrito requer uma licença válida de autorização devendo o utilizador aceder ao(s) documento(s) a partir de um endereço de IP da instituição detentora da supramencionada licença.

Ao utilizador é apenas permitido o descarregamento para uso pessoal, pelo que o emprego do(s) título(s) descarregado(s) para outro fim, designadamente comercial, carece de autorização do respetivo autor ou editor da obra.

Na medida em que todas as obras da UC Digitalis se encontram protegidas pelo Código do Direito de Autor e Direitos Conexos e demais legislação aplicável, toda a cópia, parcial ou total, deste documento, nos casos em que é legalmente admitida, deverá conter ou fazer-se acompanhar por este aviso.

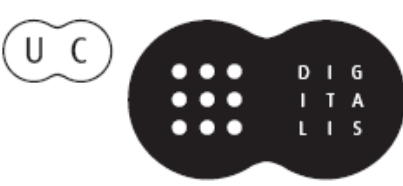




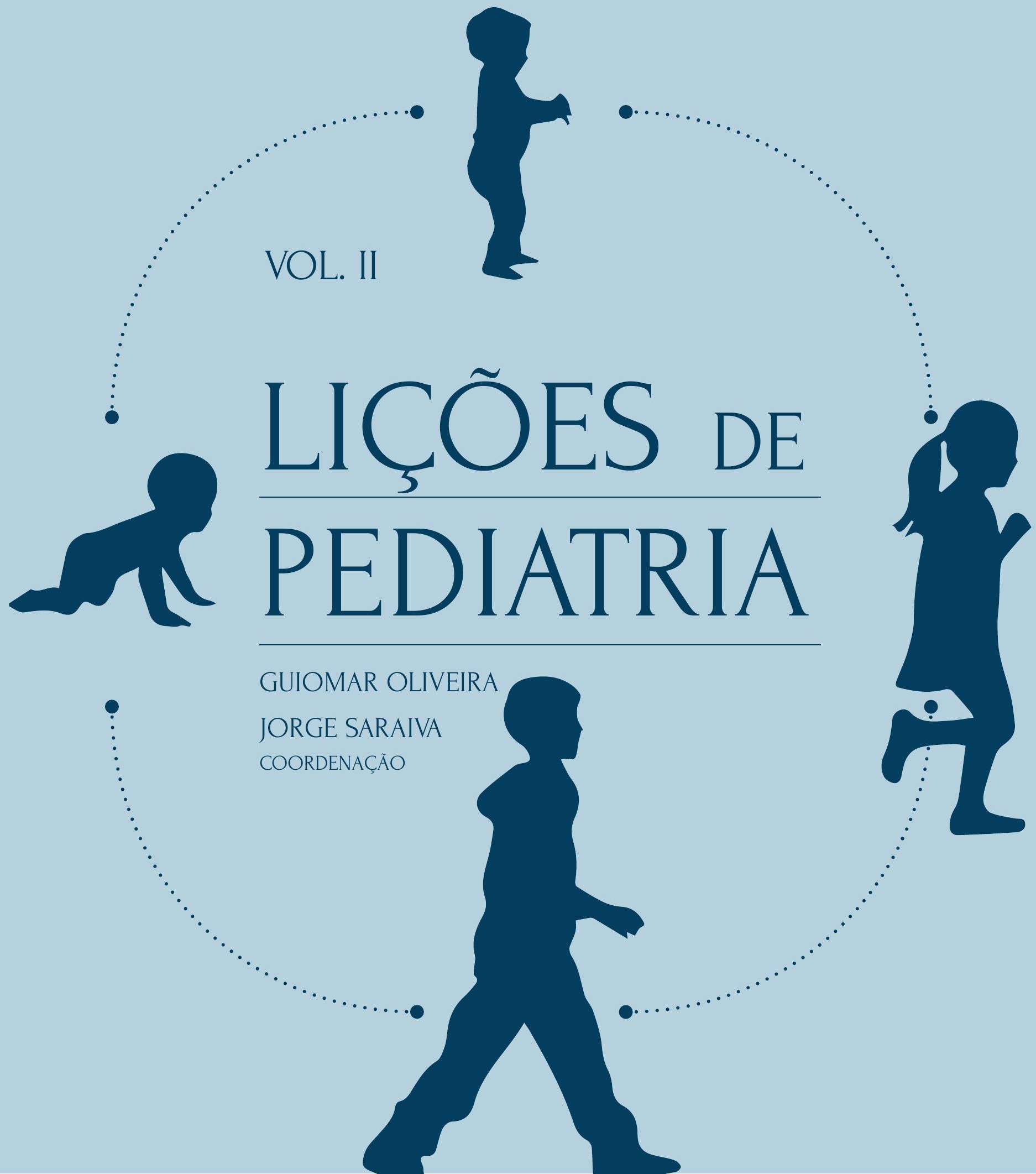


Capítulo 41.

Doenças cardíacas mais comuns

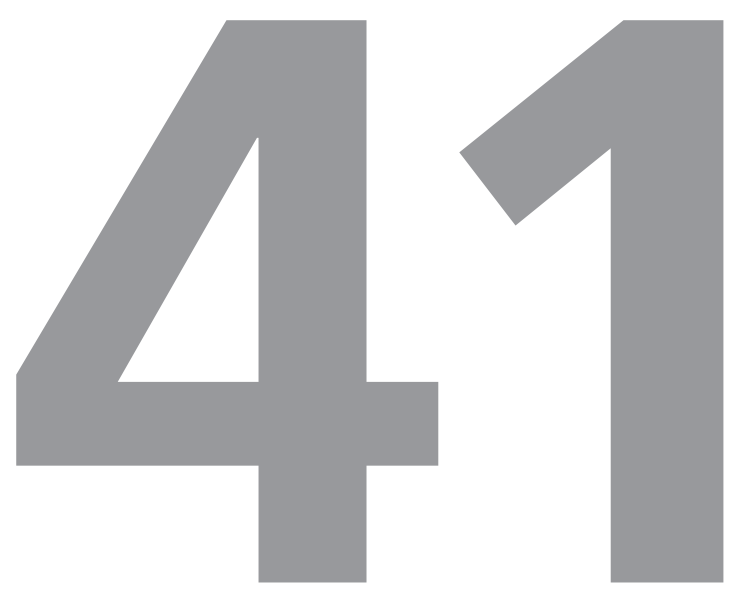

\section{António Pires}




\subsection{CONTEXTO}

Em idade pediátrica, das patologias que mais frequentemente se associam a uma significativa morbi-mortalidade, destacam-se as do foro cardíaco. Daí que, a sintomatologia cardíaca é uma causa frequente de referenciação, mesmo quando manifestamente benigna, como é o caso das síncopes vaso-vagais, a dor torácica de origem músculo-esquelética ou as palpitações.

Como tal, é importante esclarecer logo à partida os sintomas e sinais clínicos que devem alertar o clínico para uma possível causa cardíaca. Qualquer doente, com as situações já referidas no texto, deve ser oportunamente observado pela Cardiologia Pediátrica se:

- tiver antecedentes de cardiopatia congénita ou adquirida.

- tiver antecedentes familiares de cardiopatia (i.e.miocardiopatia hipertrófica) ou morte súbita.

- as queixas se associam ao esforço (quer durante, quer após).

- for portador de outras doenças com envolvimento cardíaco.

De seguida serão abordadas as doenças cardíacas, congénitas e adquiridas, mais comuns.

\subsection{DESCRIÇÃO DO TEMA}

\subsubsection{Cardiopatias congénitas}

Definem-se como anomalias da estrutura ou função do sistema cardiovascular, presentes ao nascimento. Têm uma incidência de cerca de 1\% (nados-vivos) e são consideradas as malformações congénitas mais frequentes. Nesta incidência não estão incluídas as duas anomalias mais comuns: a bicúspidia aórtica e o prolapso da válvula mitral. Nem sempre são anomalias isoladas e podem associar-se a vários síndromes como é o caso da trissomia 21, síndromes de Williams e de Turner, entre outros.

Podemos classificá-las como acianóticas,

cianóticas e obstrutivas, que passaremos a descrever. É importante referir que algumas arritmias são igualmente de origem congénita e serão discutidas em parágrafo próprio.

As cardiopatias que serão discutidas nesta secção são a comunicação interauricular (CIA), a comunicação interventricular (CIV) e a persistência do canal arterial (PCA), a tetralogia de Fallot, a transposição das grandes artérias (TGA), a coartação da aorta (CoAo), a estenose valvular pulmonar (EP), o síndrome de Wolf-ParkinsonWhite, o síndrome do QT Longo, a miocardite e a doença de Kawasaki.

\subsubsection{Cardiopatias congénitas acianóticas}

Implicitamente não cursam com cianose e a manifestação clínica mais habitual é o sopro cardíaco. Quando a malformação é hemodinamicamente significativa, evidenciam-se então sinais de insuficiência cardíaca congestiva. Neste grupo também se incluem algumas cardiopatias obstrutivas, como é o caso da estenose valvular pulmonar, que será discutida na secção " Cardiopatias obstrutivas".

\subsection{Comunicação Interauricular Incidência}

5 a 10\% das cardiopatias congénitas. Mais frequente quando se associa a outras cardiopatias 
congénitas mais complexas (30 a 50\%), e é mais frequente no sexo feminino (2:1).

\section{Tipos}

As formas mais comuns são o tipo ostium secundum (50\%); o tipo ostium primum (30\%), componente habitual de uma outra cardiopatia, o defeito do septo aurículo-ventricular, frequente nas crianças com trissomia 21; e o tipo sinus venosus (10\%), que habitualmente se associa aos retornos venosos pulmonares anómalos.

\section{Fisiopatologia}

Devido à comunicação entre as aurículas ocorre um "shunt" da aurícula esquerda (por maior pressão dentro desta cavidade) para a aurícula direita, condicionando uma sobrecarga de volume nas cavidades direitas do coração e da vasculatura pulmonar com subsequente dilatação destas estruturas.

\section{Clínica}

O aumento do fluxo de sangue através das válvulas tricúspide e pulmonar resulta nas seguintes alterações: desdobramento fixo do segundo tom cardíaco (S2) (normalmente durante a inspiração existe desdobramento do S2, mas na CIA deixa de haver esse desdobramento) e um sopro sistólico de ejeção. É raro o quadro de insuficiência cardíaca congestiva.

\section{Tratamento}

Depende das dimensões da comunicação e resultante impacto hemodinâmico. As CIAs pequenas (inferiores a três $\mathrm{mm}$ ) praticamente todas encerram espontaneamente.

Se houver indicação para encerramento, atualmente preconiza-se o encerramento percutâneo do defeito. O encerramento cirúrgico é reservado para as comunicações de maiores dimensões.

- Não está indicada a profilaxia da endocardite bacteriana.

- Não existem contra-indicações à prática do desporto, mesmo após a correção percutânea/ cirúrgica.

\subsection{Comunicação Interventricular Incidência}

Cardiopatia congénita mais frequente (15 a $20 \%$ ), excluindo a associação com outras cardiopatias mais complexas. A incidência é semelhante entre géneros.

\section{Tipos}

Perimembranosa (70\%) e muscular. A CIV de câmara de entrada, à semelhança da CIA tipo ostium primum, relaciona-se com os defeitos do septo aurículo-ventriculares.

\section{Fisiopatologia}

Quanto maiores as dimensões da comunicação, maior o "shunt" interventricular e, consequentemente maior o fluxo de sangue para a vasculatura pulmonar. Este aumento do fluxo pulmonar também depende da resistência vascular pulmonar e, quanto menor, maior também o "shunt" pulmonar. O aumento do fluxo sanguíneo resulta na sobrecarga de volume nas cavidades cardíacas esquerdas e na dilatação destas. Esta sobrecarga de volume resulta no aumento na pressão nas cavidades esquerdas e se mantida, em edema pulmonar.

Clínica - o sinal clínico mais evidente é o sopro holosistólico, pois o "shunt" interventricular 
ocorre continuamente durante a sístole e é mais acentuado à esquerda do bordo inferior do esterno. Se a CIV for restritiva será possível palpar um frémito precordial. Em casos de se associar hipertensão arterial pulmonar, o S2 estará mais intenso.

A referir que recém-nascidos com comunicações interventriculares (CIVs) hemodinamicamente significativas raramente apresentam um quadro de insuficiência cardíaca devido à elevada resistência vascular pulmonar típica desta faixa etária. No entanto, por volta das quatro a seis semanas de vida, quando estas atingem valores normais, surgem então os sinais clínicos sugestivos de insuficiência cardíaca (má progressão ponderal, taquipneia, taquicardia, galope e hepatomegália, entre outros).

\section{Tratamento}

Cerca de 30 a $40 \%$ das CIVs encerram espontaneamente, exceto as CIVs de câmara de entrada. As CIVs restritivas não necessitam de qualquer tipo de tratamento. Quando hemodinamicamente significativas, o tratamento cirúrgico é o mais indicado. A salientar que é possível o encerramento percutâneo das CIVs, particularmente das musculares, mas este deve ser contemplado apenas em crianças mais velhas.

- Está indicada a profilaxia da endocardite bacteriana, mesmo após o tratamento cirúrgico, se mantiver defeitos residuais.

- Não existem contra-indicações à prática do desporto, mesmo após a correção cirúrgica, salvo terem ocorrido sequelas importantes, como o bloqueio aurículo-ventricular pós cirúrgico.

\subsection{Persistência do canal arterial}

\section{Incidência}

5 a 10\% das cardiopatias congénitas, sendo esta incidência muito superior nos recém-nascidos prematuros ou quando associado a outras cardiopatias congénitas mais complexas. É mais frequente no sexo feminino (3:1).

O canal arterial é uma estrutura tubular que conecta a aorta descendente à artéria pulmonar. A sua patência durante a vida fetal é essencial para a sobrevivência do feto. Após o nascimento o aumento da pressão parcial de oxigénio e a diminuição das prostaglandinas circulantes determinam o seu encerramento, que normalmente ocorre espontaneamente nas primeiras 48 horas de vida. Nas cardiopatias mais complexas o encerramento do canal arterial coincide com as manifestações clínicas dessas patologias (ver mais à frente). A incidência é semelhante entre géneros.

\section{Tipos}

São vários os tipos morfológicos da persistência do canal arterial (classificação de Krichenko).

\section{Fisiopatologia}

A magnitude do "shunt" entre a aorta descendente e a artéria pulmonar e, como tal, a magnitude do resultante hiperfluxo pulmonar dependem da resistência imposta a este "shunt" pelo canal arterial, nomeadamente da morfologia do próprio canal arterial (diâmetro, comprimento, tortuosidade) e da resistência arterial pulmonar. Quanto maior a dimensão do canal arterial e menor a resistência vascular pulmonar, maior o fluxo pulmonar. À semelhança da CIV, 
o hiperfluxo pulmonar resulta na dilatação das cavidades esquerdas do coração.

Clínica- o sinal clínico mais evidente é o sopro contínuo, pois o "shunt" através do canal arterial ocorre durante a sístole e a diástole. Tal como no caso da CIV, se o canal arterial for hemodinamicamente significativo é de esperar nestas crianças um quadro de insuficiência cardíaca congestiva.

\section{Tratamento}

O tratamento da PCA pode ser farmacológico, percutâneo ou cirúrgico.

O tratamento farmacológico com anti-inflamatórios não esteróides (ibuprofeno, indometacina) é limitado a recém-nascidos prematuros com canais arteriais hemodinamicamente significativos. Os recém-nascidos de termo não respondem a estas medidas pois a PCA neste grupo de doentes deve-se a uma alteração estrutural e não à idade gestacional.

Na grande maioria dos casos recorre-se ao encerramento percutâneo, salvo nos recém-nascidos prematuros de muito baixo peso que não respondem ao tratamento farmacológico ou quando o canal arterial é de grandes dimensões, impossibilitando a colocação de dispositivos. Nestes, a laqueação cirúrgica é o procedimento mais indicado.

- Está indicada a profilaxia da endocardite bacteriana.

- Não existem contra-indicações à prática do desporto, mesmo após a correção percutânea/ cirúrgica.

Nota: o síndrome de Eisenmenger é uma doença obstrutiva vascular pulmonar que se desenvolve no caso de patologias com "shunts" esquerdo-direito significativos não serem corrigidas atempadamente. Ocorre inversão do "shunt" por aumento das pressões nas cavidades direitas do coração devido ao aumento das resistências pulmonares, e habitualmente implica que a patologia subjacente se torne inoperável.

\subsubsection{Cardiopatias congénitas cianóticas}

A cianose evidencia-se clinicamente quando existe cerca de $5 \mathrm{~g} / \mathrm{dL}$ de hemoglobina desoxigenada no sangue e a saturação periférica de oxigénio é aproximadamente de $80 \%$. Nas cardiopatias congénitas cianóticas, a cianose resulta da mistura de sangue venoso com o arterial. Em caso de anemia, este sinal clínico pode não ser percetível.

\subsection{Tetralogia de Fallot}

\section{Incidência}

10\% das cardiopatias congénitas. É a cardiopatia cianótica mais frequente fora do período neonatal. Tem incidência semelhante entre géneros.

\section{Caraterísticas morfológicas}

Anomalia composta por uma CIV sub-aórtica larga, obstrução da câmara de saída do ventrículo direito, habitualmente a nível infundibular, uma válvula aórtica mal-alinhada que "cavalga" o septo interventricular e hipertrofia ventricular direita.

\section{Fisiopatologia}

A cianose depende do grau do obstáculo ao fluxo pulmonar. Podem ocorrer episódios súbitos de cianose grave secundários a um "shunt" direito-esquerdo, as chamadas "crises cianóticas". 


\section{Clínica}

A cianose não se manifesta inicialmente mas é progressiva. O sopro sistólico audível no foco pulmonar é o sinal auscultatório mais evidente e deve-se ao obstáculo pulmonar. Durante as crises cianóticas este sopro desaparece devido à diminuição do fluxo pulmonar, visto o sangue ser desviado através da CIV para o lado esquerdo do coração.

\section{Tratamento}

O tratamento definitivo da tetralogia de Fallot é cirúrgico, em que se encerra a CIV e se alarga o trato de saída do ventrículo direito. O propranolol utiliza-se profilaticamente para evitar as crises cianóticas. As crises cianóticas são emergências cardíacas e necessitam de tratamento imediato, que inclui a posição de cócaras, administração de morfina e de bicarbonato de sódio. O início destes episódios sinaliza um agravamento do quadro clínico e deve-se nesta fase acelerar a correção cirúrgica.

- Está recomendada a profilaxia da endocardite bacteriana.

- Nas crianças operadas não existem contra-indicações à prática do desporto, salvo se tiveram sequelas pós cirúrgicas importantes.

\subsection{Transposição das grandes artérias (TGA)}

\section{Incidência}

0,2 a 0,4/1.000 nados-vivos. É a cardiopatia cianótica mais frequentemente diagnosticada durante o período neonatal. É mais frequente no sexo masculino (3:1).

\section{Caraterísticas morfológicas}

Existe uma discordância ventrículo-arterial. A aorta (Ao) tem origem no ventrículo direito (VD) e a artéria pulmonar (AP) no ventrículo esquerdo (VE).

\section{Fisiopatologia}

Dada a discordância ventrículo-arterial existem duas circulações em paralelo (VD-Ao; VE-AP) resultando numa ineficaz oxigenação da circulação sistémica. Esta só é possível se existirem em uma ou mais comunicações entre estas circulações (i.e. CIA, CIV ou PCA).

\section{Clínica}

Devido às circulações em paralelo, a cianose manifesta-se precocemente (nas primeiras horas de vida), que se não for corrigida resulta na morte do recém-nascido. A cianose não responde à oferta de oxigénio. O sopro cardíaco é um achado raro.

\section{Tratamento}

O tratamento definitivo da TGA é cirúrgico, e habitualmente é realizado nas primeiras semanas de vida. No entanto, logo à nascença é emergente corrigir a cianose, o que implica a administração de prostaglandina E1 ( mantem o canal arterial patente) e realizar o procedimento de Rashkind (para criar uma CIA), possibilitando a mistura de sangue venoso e arterial melhorando assim a oxigenação do leito sistémico.

- Está recomendada a profilaxia da endocardite bacteriana.

- Nas crianças operadas não existem contra-indicações à prática do desporto, salvo 
se tiverem sequelas pós cirúrgicas importantes.

\subsubsection{Cardiopatias obstrutivas}

\subsection{Coartação da aorta}

\section{Incidência}

8 a 10\% das cardiopatias congénitas. É mais frequente no sexo masculino (2:1). Ocorre em cerca de $30 \%$ dos doentes portadores de síndrome de Turner.

\section{Caraterísticas morfológicas}

A grande maioria localiza-se na região justa-ductal, distal à artéria subclávia esquerda. A anomalia cardíaca que mais frequentemente se associa à coartação da aorta é a bicúspidia aórtica (85\% dos doentes). Cerca de 5 a 10\% dos doentes com CoAo tem aneurismas intracerebrais (aneurismas de Berry).

\section{Fisiopatologia}

Sendo um obstáculo esquerdo condiciona um aumento da sobrecarga por pressão nas cavidades esquerdas do coração. Trata-se portanto de um exemplo de uma cardiopatia em que verifica um aumento da póscarga com possível compromisso do débito cardíaco.

\section{Clínica}

Deve-se suspeitar quando existe um diferencial da pressão arterial entre os membros superiores e os membros inferiores de $20 \mathrm{mmHg}$ ou mais. Dependendo do grau de obstrução, são possíveis dois quadros clínicos, sendo os mais habituais: choque cardiogénico coincidente com o encerramento do canal arterial no recém-nascido com coartação da aorta grave (o canal arterial permite a manutenção do fluxo sistémico através da artéria pulmonar, visto não haver passagem de sangue pela aorta) ou crianças assintomáticas com hipertensão arterial apenas nos membros superiores e com diminuição dos pulsos femorais à palpação. Nestas, também pode ser percetível um sopro sistólico de ejeção audível na região superior do bordo direito do esterno e/ou no dorso.

\section{Tratamento}

Nos recém-nascidos com choque cardiogénico é emergente iniciar prostaglandinas E1 para manter o canal arterial patente. Após estabilização hemodinâmica o tratamento definitivo é cirúrgico.

Nas crianças assintomáticas duas possibilidades existem: a angioplastia percutânea e, caso esta não seja bem-sucedida, a correção cirúrgica. Também devem ser submetidas a correção cirúrgica as coartações da aorta mais complexas, como é o caso da CoAo com hipoplasia do arco aórtico.

\subsection{Estenose pulmonar (EP)}

\section{Incidência}

8 a 12\% das cardiopatias congénitas. A EP é frequentemente associada a outras cardiopatias mais complexas como é o caso da tetralogia de Fallot. A incidência é idêntica entre géneros.

\section{Caraterísticas morfológicas}

A estenose pulmonar pode ser de origem valvular (frequente nas crianças com síndrome de Noonan), infundibular (como é o caso na tetralogia de Fallot) e supravalvular (mais frequente nas crianças com síndrome de Williams). 


\section{Fisiopatologia}

Sendo um obstáculo direito pode condicionar uma sobrecarga por pressão nas cavidades direitas do coração, resultando em hipertrofia e dilatação do ventrículo direito. Pode, nos casos mais graves (estenose crítica da pulmonar), comprometer o débito pulmonar e implicitamente o débito sistémico.

\section{Clínica}

Depende do grau de obstrução. Recémnascidos com estenose crítica da pulmonar manifestam cianose precocemente, que mais uma vez, coincide com o encerramento do canal arterial. Nas crianças mais velhas, um sopro sistólico de ejeção mais audível no segundo espaço intercostal esquerdo (foco pulmonar) é o achado clínico mais evidente.

\section{Tratamento}

Nos recém-nascidos com estenose crítica da artéria pulmonar é emergente iniciar prostaglandinas E1 para manter o canal arterial patente e, assim, manter o débito pulmonar para que o sangue possa ser oxigenado. Após estabilização do doente a perfuração percutânea ou cirúrgica são opções terapêuticas ao nosso dispor.

Nas crianças assintomáticas, dependendo do grau de obstrução, a dilatação percutânea é o procedimento mais comum.

\subsubsection{Alterações da condução cardíaca}

\subsubsection{Síndrome de Wolf-Parkinson-White}

Em idade pediátrica o síndrome de WolfParkinson-White (S.WPW) é o mais comum dos síndromes de pré-excitação (ativação precoce) ventricular. Deve-se à presença de uma via acessória entre as aurículas e os ventrículos, em que o impulso cardíaco despolariza diretamente os ventrículos fazendo um bypass ao nódulo aurículo-ventricular.

Refere-se a "padrão de Wolf-Parkinson White" se existirem apenas alterações eletrocardiográficas que tipicamente caraterizam esta anomalia da condução cardíaca. Quando se associa a uma arritmia, aí usamos o termo "síndrome de WPW".

\section{Incidência}

O padrão WPW está presente em cerca de 0,1 a $0,3 \%$ da população. A incidência é superior nos parentes de primeiro grau portadores deste padrão (0,5\%). A incidência do síndrome é substancialmente mais baixa, variando entre 0,07 a 0,12\%. Cerca de 20 a 30\% dos doentes com o padrão WPW desenvolve arritmias, das quais a taquicardia supraventricular (TSV) é a mais comum. Esta arritmia, a TSV, durante a infância tem dois picos de incidência: primeiro ano de vida e adolescência. Menos frequente á a fibrilação auricular, no entanto, mais preocupante pois pode resultar na fibrilação ventricular e maior risco de morte súbita.

A cardiopatia congénita que mais frequentemente se associa ao síndrome de WPW é a anomalia de Ebstein da válvula tricúspide, embora, na grande maioria dos casos não se correlacione com outras cardiopatias congénitas.

\section{Caraterísticas}

O diagnóstico de síndrome de WPW é eletrocardiográfico. A condução do impulso cardíaco através da via anómala resulta em: intervalo PR curto, complexo QRS largo, onda delta (inflexão inicial do complexo QRS). 


\section{Clínica}

A maioria dos portadores de sindrome WPW é assintomático. As manifestações clínicas da TSV variam desde um desconforto precordial à descompensação cardíaca por baixo débito, particularmente nas idades mais precoces.

As crises de TSV são emergências cardíacas. As medidas usadas para tratar esta taquicardia incluem: manobras vagais (gelo na face nos lactentes), adenosina e, se necessário, cardioversão elétrica.

O tratamento crónico consiste em administrar beta-bloqueantes para prevenir as crises de TSV. Em idade apropriada a ablação por rádio-frequência é curativa em cerca de 95\% dos casos.

- A prática do desporto depende da resposta ao esforço. Se durante uma prova de esforço se desencadearem arritmias, o desporto não é permitido.

\subsubsection{Síndrome do QT Longo}

O síndrome do QT Longo (SQTL) caracteriza-se por um prolongamento do intervalo QT no eletrocardiograma e por um risco aumentado de morte súbita.

\section{Incidência}

1/25.000 a 10.000 na população, em geral. Em relação às crianças com surdez congénita, estima-se que entre 0,3 a 3,7\% tenham SQTL. Apesar de ser mais frequente no sexo feminino, a mortalidade é superior nos rapazes.

\section{Caraterísticas}

O SQTL pode ser congénito ou adquirido. As formas congénitas, causadas por mutações genéticas que codificam canais iónicos cardíacos, são habitualmente autossómicas dominantes. As formas recessivas têm um fenótipo mais agressivo e podem associar-se a surdez neuro-sensorial.

As formas adquiridas são causadas por vários estímulos, como, por exemplo, distúrbios metabólicos, eletrolíticos ou fármacos. Ao contrário das formas congénitas, as formas adquiridas são reversíveis após correção da causa subjacente.

Até á data foram identificadas mutações em 13 genes, pelo que existem 13 tipos de SQTL, designados de SQTL 1 a 13, sendo os três primeiros os mais frequentes.

O diagnóstico é feito através da medição do intervalo QT em função da frequência cardíaca (ajustada à idade e género), ou seja, o intervalo QT corrigido (QTC). Para se calcular o QTc utiliza-se a fórmula de Bazett (QTc= intervalo QT/Vintervalo $\mathrm{RR})$.

\section{Clínica}

Os doentes portadores de SQTL podem manifestar um espetro de manifestações clínicas, tal como, palpitações, lipotimias, síncope, paragem cardíaca e morte súbita.

É habitualmente associado a uma forma de taquicardia ventricular conhecida por Torsades de Pointes que, em grande parte, é desencadeada por vários fatores externos, nomeadamente, exercício, mergulhar e ruídos (despertador, telefone). Episódios repetidos podem induzir síncope ou progredir para a fibrilhação ventricular.

\section{Tratamento}

Os principais objetivos do tratamento do SQTL congénito são a prevenção da morte súbita e a diminuição da sintomatologia. Não existe uma terapêutica curativa. 
Devem-se instituir medidas gerais tais como evitar o consumo de fármacos que prolonguem o intervalo QT e atividades físicas intensas.

Todos os doentes com SQTL devem ser medicados com beta-bloqueantes. Estes reduzem a incidência de morte súbita de $50 \%$ para $5 \%$.

Nos doentes de alto risco (i.e. sobreviventes de paragem cardíaca) deve-se considerar a implantação de um cardiodesfibrilhador implantável.

- A prática de desporto está contra-indicada.

\subsubsection{Cardiopatias adquiridas}

\subsubsection{Miocardite}

A miocardite define-se como uma inflamação do miocárdio. Apesar de várias causas estarem implicadas na génese da miocardite, as infeciosas são as mais comuns. Destas, as infeções víricas são as mais frequentes, principalmente as causadas pelos adenovírus e enterovírus (coxsackie B). O parvovírus, embora menos comum, associa-se a quadros clínicos mais graves.

\section{Incidência}

Dada a variabilidade clínica da doença a verdadeira incidência da miocardite virusal é desconhecida. Estima-se que 1 a $5 \%$ de doentes com infeções virusais agudas tenham atingimento do miocárdio, embora a grande maioria sem qualquer evidência de descompensação cardíaca.

\section{Fisiopatologia}

A miocardite é uma doença trifásica: dá-se inicialmente a invasão direta do miocárdio pelo vírus, seguido de uma resposta auto-imune do qual resulta uma lesão do miocárdio e por fim a miocardiopatia dilatada. Esta última fase corresponde habitualmente à fase clínica, sendo as duas primeiras fases consideradas assintomáticas.

\section{Clínica}

As manifestações clínicas são variáveis. As crianças assintomáticas (provavelmente apenas com alterações inespecíficas no eletrocardiograma) ou aquelas com insuficiência cardíaca mas com função contrátil preservada evoluem favoravelmente. O mesmo não acontece nas crianças com miocardiopatia dilatada, em que apenas 25\% recupera totalmente.

\section{Diagnóstico}

Apesar do exame gold standard ser a biópsia endomiocárdica, em idades pediátricas é limitado pelo seu caráter invasivo. O ecocardiograma é uma ferramenta extremamente útil na avaliação de doentes com miocardite. Permite o diagnóstico de miocardiopatia dilatada e avalia o grau de disfunção cardíaca. Outros exames imagiológicos a que podemos recorrer são a ressonância magnética e a cintigrafia cardíaca.

Analiticamente as troponinas cardíacas sugerem necrose miocárdica e estão habitualmente elevadas nas miocardites víricas.

A avaliação etiológica depende do contexto clínico. Por exemplo, em caso de um processo infecioso recente, deve-se proceder a estudos de pesquisa virusal.

\section{Tratamento}

Na fase aguda da doença, um doente com descompensação cardíaca por disfunção contrátil pode necessitar da administração de inotrópicos 
vasodilatadores e de terapêutica anti-congestiva. Posteriormente, os diuréticos, os inibidores da enzima de conversão da angiotensina e os beta-bloqueantes constituem a terapêutica de base desta patologia.

\subsubsection{Doença de Kawasaki}

A doença de Kawasaki (ver lição de exantemas) é uma vasculite sistémica de etiologia desconhecida, atingindo principalmente as pequenas e médias artérias, em particular, as artérias coronárias e condicionando a formação de aneurismas coronários (25\% em doentes não medicados).

É, atualmente, a principal causa de cardiopatia adquirida em países desenvolvidos.

\section{Incidência}

Afeta 3,4 a 100/100.000 crianças, com um predomínio no sexo masculino (1,5:1). Ocorre essencialmente em crianças abaixo dos cinco anos de idade, com uma média de dois anos. A taxa de mortalidade pode atingir os $2 \%$, particularmente em crianças com menos de dois anos.

\section{Diagnóstico e clínica}

Os critérios propostos pela American Heart Association para o diagnóstico da doença de Kawasaki são:

\section{febre elevada com pelo menos cinco dias de evolução, e quatro dos cinco sinais clínicos:}

i) hiperémia conjuntival bulbar bilateral sem exsudato;

ii) alterações da mucosa oral; iii) alterações a nível das mãos e pés (edema, rubor, descamação);

iv) exantema polimorfo; e

v) linfadenopatia cervical (diâmetro $>1,5 \mathrm{~cm}$ ).

Trata-se de uma doença trifásica, com a seguinte evolução:

- fase aguda: dura cerca de uma a duas semanas e coincide com o aparecimento dos sinais clínicos. Nesta fase normalmente não se observam aneurismas coronários.

- fase sub-aguda: dura entre duas a quatro semanas. Observa-se a resolução dos sinais clínicos constatados anteriormente e surgem a descamação dos dedos, a trombocitose e os aneurismas coronários. É nesta fase que há maior risco de morte.

- fase de convalescença: sete a oito semanas após o início do quadro clínico e coincide com a normalização dos biomarcadores inflamatórios (velocidade de sedimentação e proteína $C$ reativa).

Face à alta probabilidade de envolvimento cardíaco, que não se limita apenas ao risco de aneurismas coronários, todos os doentes devem realizar uma ecocardiografia na altura do diagnóstico da doença, à segunda semana de doença (coincide com o aparecimento dos aneurismas) e entre a sexta e a oitava semana de doença (controlo dos aneurismas e, particularmente da resposta à terapêutica instituída).

Existe também o diagnóstico de doença de Kawasaki incompleta ou atípica que se carateriza por quadro de febre inexplicada com duração 
de pelo menos cinco dias e três dos critérios já referidos. O diagnóstico desta entidade exige um alto grau de suspeição.

\section{Tratamento}

Na doença de Kawasaki o principal objetivo do tratamento é reduzir a incidência da doença coronária. A estratégia terapêutica inclui a administração de imunoglobulina (que reduz a incidência de aneurismas para 5\%) que deve ser administrada idealmente nos primeiros dez dias da doença e o ácido acetilsalicílico em doses anti-inflamatórias. Após a fase aguda, o ácido acetilsalicílico é reduzido para doses anti-agregantes plaquetárias até à normalização da velocidade de sedimentação e do valor de plaquetas, desde que não haja evidência de envolvimento coronário.

\section{Leitura complementar}

Park; Myung. Park's Pediatric Cardiology for Practitioners, 6th Edition. Philadelphia: Elsevier Saunders, 2014. Print 